\title{
A INTERDISCIPLINARIDADE E O TRABALHO COLETIVO: ANÁLISE DE UM PLANEJAMENTO INTERDISCIPLINAR
}

\author{
Interdisciplinary and collective work: analysis of an \\ interdisciplinar planning
}

\author{
Célia Weigert ${ }^{1}$ \\ Alberto Villani \\ Denise de Freitas ${ }^{3}$
}

\begin{abstract}
Resumo: Neste trabalho apresentamos os resultados do processo de construção de um trabalho coletivo e interdisciplinar desenvolvido numa parceria entre uma escola de Ensino Médio e outras instituições de ensino e de pesquisa. Serão apresentadas as várias fases da experiência, que foi interpretada a partir de referenciais teóricos da interdisciplinaridade e da psicanálise de grupo. A reconstrução do processo deu-se a partir da fala das professoras e pesquisadoras envolvidas no projeto.
\end{abstract}

Unitermos: psicanálise e educação; formação de professores; interdisciplinaridade; grupos

Abstract: The paper shows the results of the construction process of a collective and interdisciplinary work developed in a partnership between a High School and other institutions of education and research. We show the different phases of the experience, which was interpreted by group psychoanalysis and interdisciplinary theoretical references. The reconstruction of the process was given from the speeches of the teachers and researchers involved in the project.

Keywords: psychoanalysis and education; in-service program; interdisciplinary work; groups

\section{Introdução}

A falta de perspectivas, tanto por parte dos educadores, quanto por parte dos educandos em relação aos benefícios gerados por um processo de ensino-aprendizagem pouco engajado com os problemas da vida cotidiana, tem levado diferentes linhas pedagógicas a pensar metodologias que forneçam aos alunos conhecimentos básicos para atender à atual demanda sócio-político-econômica da realidade brasileira. Muitas pesquisas tratam dessa mudança que está ocorrendo no sentido da educação mundial, com enfoques diferentes, sugerindo alternativas diversas que propiciem um aprendizado significativo para o aluno e, ao mesmo tempo, uma formação/capacitação ao professor. No âmbito escolar a discussão sobre a interdisciplinaridade vem ganhando destaque nos últimos anos a partir da publicação dos Parâmetros Curriculares Nacionais em 1997, que trazem uma proposta de reforma no sistema de ensino baseada em mudanças no conhecimento e seus desdobramentos no que se refere à produção e às relaçôes sociais de modo geral (Parâmetros Curriculares Nacionais, 1997: 6). A preocupação, de modo geral, explicitada neste documento, é com o volume de informações cada vez maior colocado à disposição da sociedade pelos meios de comunicação e como estas informações podem ser utilizadas para que o cidadão compreenda melhor o mundo natural e social.

A proposta apresentada pelos PCN sugere que a formação dos alunos tenha um caráter mais geral, possibilitando-lhes o desenvolvimento de capacidades que os habilitem a utilizar as diferentes tecnologias; assim, prioriza como proposta metodológica a investigação, para

\footnotetext{
${ }^{1}$ Mestre em Ensino de Ciências - Unesp. Com auxílio da Capes/DS. E-mail: celiaweigert@itelefonica.com.br

${ }^{2}$ Professor Associado do Instituto de Física da Universidade de São Paulo. Com auxílio parcial do CNPq.

E-mail:avillani@if.usp.br

${ }^{3}$ Professora Adjunta do Departamento de Metodologia de Ensino da Universidade Federal de São Carlos. Com auxílio parcial do CNPq. E-mail: dfreitas@power.ufscar.br
} 
que o aluno possa exercitar sua capacidade de buscar informaçóes e analisá-las, de forma significativa, deixando de lado o hábito da memorização. Para atingir estes objetivos, os PCN trazem uma idéia de interdisciplinaridade que requer uma mudança no currículo da escola e para isso: Propôs-se, numa primeira abordagem, a reorganização curricular em áreas de conhecimento, com o objetivo de facilitar o desenvolvimento dos conteúdos, numa perspectiva de interdisciplinaridade e contextualização (PCN, 1997:8).

No âmbito dessas discussões, o Programa de Ensino do Projeto Flora Fanerogâmica do Estado de São Paulo, um projeto temático financiado pela Fapesp, foi proposto para contribuir com a melhoria do ensino da rede pública, mais especificamente, em relação aos conhecimentos de Botânica, explorando uma metodologia interdisciplinar. $\mathrm{O}$ projeto envolveu várias Instituições (Universidades, Escolas e Fapesp) com a finalidade de propiciar a elaboração de um projeto coletivo que integrasse as práticas diárias em sala de aula de vários professores e, portanto, de várias disciplinas do Ensino Médio.

No entanto, a introdução de uma inovação envolve algumas dificuldades. Entre as apontadas por Huberman (1973), duas delas, por estarem diretamente envolvidas com o caráter coletivo inerente à metodologia interdisciplinar, podem nos ajudar a compreender melhor o comportamento das professoras durante o desenvolvimento deste programa de ensino. De um lado, as mudanças que envolvem grupos interdisciplinares de professores são mais lentas e despendem mais energia para se efetivarem. Ou seja, é mais difícil constituir um grupo de trabalho eficiente com professores que falam "línguas diferentes". A metodologia interdisciplinar prevê a integração de áreas diferentes, portanto, necessitam de um tempo maior de diálogo entre os membros do grupo, mais disponibilidade para aceitar a diferença e para conhecer as contribuições que cada disciplina pode dar na construção, ou na reconstrução, de um conhecimento contextualizado. Por outro lado, as inovações que envolvem a metodologia interdisciplinar são mais difíceis de serem aceitas, pois sua utilidade encontra mais obstáculos para ser reconhecida. Em geral, uma mudança que implica um avanço interdisciplinar pressupõe uma outra atitude disciplinar, em que os alunos ganham mais liberdade de atuação em sala de aula, ou seja, o professor não prioriza o "aluno comportado", mas sim o "aluno participante"; os críticos da mudança ou os próprios participantes sempre podem focalizar esse aspecto como uma perda. Por isso, parecem muito necessárias pesquisas que analisem experiências didáticas envolvendo grupos interdisciplinares.

Neste artigo analisaremos parte do Programa de Ensino do Projeto Flora Fanerogâmica, que consistiu a implementação de um planejamento interdisciplinar numa escola com o objetivo de divulgar os resultados do correspondente projeto temático - Projeto Flora Fanerogâmica do Estado de São Paulo - e tornar o conteúdo de Botânica mais atraente para alunos e professores. Nosso foco será tentar responder às perguntas: quais dificuldades, mudanças e recuos, negociações e compromissos foram envolvidos na elaboração e realização do planejamento interdisciplinar? Qual a dinâmica grupal estabelecida entre os integrantes do projeto?

A partir das dificuldades e das conquistas apresentadas pelo grupo Flora para implementar as mudanças que foram propostas, poderemos refletir sobre alguns aspectos envolvidos nesse processo. Inicialmente descreveremos o contexto da experiência, a metodologia de pesquisa adotada e o referencial teórico utilizado. Em seguida, relataremos as várias fases das experiências que interpretaremos a partir dos referenciais teóricos da interdisciplinaridade e da psicanálise de grupo. Este desenvolvimento será reconstruído pelas falas das professoras e das pesquisadoras envolvidas neste processo. Espera-se que os resultados da análise forneçam pistas para facilitar a organização de grupos de trabalho, tanto dentro da sala de aula com os alunos, quanto em cursos de capacitação e formação de professores. As considerações finais pretendem 
A interdisciplinaridade e o trabalho coletivo...

trazer elementos que ajudem a compreender processos importantes que ocorrem em trabalhos coletivos, principalmente na construção interdisciplinar.

\section{A Metodologia de Pesquisa}

\section{O Contexto da Experiência}

O Projeto Flora Fanerogâmica do Estado de São Paulo, financiado pela Fapesp, tinha como objetivo conhecer a vegetação remanescente do estado e difundir os conhecimentos e experiências adquiridas durante o seu desenvolvimento, com a publicação dos resultados para a sociedade. Assim, um desdobramento na área educacional facilitaria a socialização do conhecimento produzido e promoveria a divulgação da importância da preservação da vegetação do Estado de São Paulo. Incentivando a parceria com a escola pública, o "Programa de Ensino do Projeto Flora Fanerogâmica do Estado de São Paulo" foi proposto para contribuir na melhoria do ensino de Botânica para o ciclo básico a partir dos conhecimentos adquiridos no desenvolvimento deste projeto temático. Adotar uma linha interdisciplinar para o Programa de Ensino traria a possibilidade de integração de conhecimentos e habilidades inerentes ao ensino de Botânica, como por exemplo, a observação, o registro da observação e o estabelecimento de relações entre os aspectos da vegetação e os aspectos físicos decorrentes da preservação ou da degradação que influenciam diretamente o desenvolvimento humano. Esperava-se que as(os) professoras(es) envolvidas(os) no projeto desenvolvessem novas metodologias, dentro de uma perspectiva interdisciplinar, possibilitando aos alunos uma postura mais crítica e consciente em relação aos problemas sociais e ambientais do seu cotidiano.

O objetivo principal era a construção de uma metodologia capaz de capturar o aluno e também o professor, ao mostrar que a Botânica pode interagir com outras áreas de conhecimento, possibilitando o rompimento da compartimentação que torna o ensino deste conteúdo tão desconectado dos aspectos sociais envolvidos com a diversidade vegetal. A integração das ações dos pesquisadores com os docentes do Ensino Básico enriqueceria o trabalho de construção da visão interdisciplinar. O programa contava com a participação de quatro cidades: em cada uma delas estavam envolvidos professores da rede pública e professores/pesquisadores de diversos institutos de pesquisa. $\mathrm{O}$ relato que segue trata exclusivamente do transcorrido numa das cidades, SC, onde o grupo era formado, por três pesquisadoras ${ }^{4}$ (dos departamentos de Botânica e de Metodologia de Ensino de uma universidade pública da cidade), por quatro professoras 5 , (de História, Biologia, Geografia e Artes de uma escola de Ensino Médio) e por alguns estagiários, entre os quais uma das pesquisadoras deste artigo foi responsável pelo registro dos dados $(\mathrm{Ce})$.

\footnotetext{
${ }^{4}$ Neste trabalho denominamos as professoras/pesquisadoras como C1, C2 e C3. C1 é bióloga, professora da Universidade exercendo cargo administrativo junto à Pró-Reitoria de Graduação: foi ela quem convocou o grupo. C2 é bióloga, professora do Departamento de Botânica e desenvolvia projetos na área de Sistemática Vegetal, foi a coordenadora oficial do projeto. C3 é bióloga, com mestrado e doutorado em Educação e é professora do Departamento de Metodologia da Educação.

${ }^{5}$ Neste trabalho denominamos as professoras da escola do Ensino Médio de PB, PG, PH e PA. PB é bióloga, professora efetiva do Ensino Médio, e tinha sido colega de C3 e aluna de C1 durante a graduação; já havia participado de outros projetos na escola envolvendo outras disciplinas. PG é geógrafa, atuava como professora substituta na rede estadual e como professora concursada na rede municipal. A PH é historiadora, professora efetiva da rede estadual, estava em processo de aposentadoria à época do projeto. PA é formada em Artes e professora substituta na rede estadual e concursada na rede municipal; já havia tido algumas experiências com trabalhos coletivos e interdisciplinares.
} 


\section{A Pesquisa}

A pesquisa foi de tipo qualitativo e participante (Bogdan \& Biklen, 1994), na qual uma das pesquisadoras atuava também como monitora e a outra como uma das coordenadoras do projeto e o enfoque dos resultados teve um caráter interpretativo. O material que serviu de suporte para as análises foi a gravação das reuniōes semanais do grupo, nas quais as professoras, coordenadoras e estagiárias participavam, durante quatro horas em média, de um diálogo reflexivo, discutindo os problemas de sala de aula e planejando o andamento das aulas da semana. Tais registros, assim como as anotaçôes que a pesquisadora $(\mathrm{Ce})$ elaborava no final das reuniōes do grupo, iniciaram somente a partir de janeiro de 1999, um mês depois do grupo analisado iniciar suas reuniōes regulares. O período anterior foi reconstruído com base nas entrevistas individuais realizadas no final da experiência com as coordenadoras e as professoras participantes do projeto. A análise dos dados foi realizada com um procedimento duplo. Em primeiro lugar procurou-se obter uma descrição do desenvolvimento geral da experiência, localizando os eventos mais importantes. Em seguida, o material foi questionado quanto às explicaçôes mais plausíveis para o desenvolvimento do grupo. Nesta etapa as pesquisadoras serviram também como fonte de dados relatando eventos ou detalhes que não tinham sido considerados na reconstrução anterior, mas que fortaleciam a plausibilidade de uma determinada interpretação. Nesta segunda etapa foram estabelecidas as fases do desenvolvimento grupal.

\section{Referenciais teóricos}

\section{A Interdisciplinaridade}

Muitos autores apresentam diferentes visōes para a construção interdisciplinar. No programa desenvolvido, e agora analisado, duas visōes exerceram uma influência marcante: a utilização de temas geradores que sustentaram a elaboração do planejamento (Pontuscka, 1993) e a convicção das professoras em transformar seus alunos em sujeitos ativos da história que constroem no seu dia-a-dia (Bochniack, 1992).

Segundo a visão de Bochniack, a interdisciplinaridade deve começar na mente das pessoas envolvidas no processo; a primeira mudança necessária para viabilizar o processo de diálogo entre os conhecimentos é a credibilidade do professor em sua função de modificador da sociedade na qual atua. Cabe ao professor preparar as geraçōes futuras para sua função de "fazedores" da história e construtores do conhecimento verdadeiro (Bochniack, 1992: 6). Para a autora, a interdisciplinaridade tem como função melhorar primeiramente a relação dos seres humanos com o conhecimento, com o entendimento do saber contextualizado, modificando a vida das pessoas ao promover a cidadania. Com este conceito, a autora revela que acredita que a interdisciplinaridade deve ser entendida como um instrumento para aproximar o conhecimento formalizado à prática cotidiana. Conseqüentemente sua metodologia prevê a ruptura de barreiras preestabelecidas, favorecendo o diálogo entre saberes diferentes.

Para Pontuschka (1993), a interdisciplinaridade se apresenta como uma metodologia em que se respeita a especificidade de cada área, procurando estabelecer e compreender as relações entre os conhecimentos sistematizados, ampliando o espaço de diálogo na direção da negociação de idéias e da aceitação de outras visōes. Em seu livro "Ousadia do diálogo" (1993), encontramos referências aos temas geradores como norteadores do estudo da realidade na tentativa de visualizar os problemas do cotidiano à luz dos conhecimentos sistematizados, buscando formas para problematizá-los e levá-los para a sala de aula. Os temas geradores desempenham o papel de eixo de equilíbrio entre uma visão geral do cotidiano e a visão específica de cada área sobre este cotidiano. A interdisciplinaridade, assim concebida, busca ampliar as concepçōes de 
A interdisciplinaridade e o trabalho coletivo...

ensino, de escola, de Educação e modificar as relações entre os diferentes segmentos envolvidos: professor, aluno, conhecimento. Sobretudo na interação aluno-professor é necessário que tanto um quanto outro abram espaço para o diálogo, para as diferenças, para as experiências pessoais relevantes. Este (o aluno) não é um simples receptáculo de conteúdos preestabelecidos, e aquele (o professor) não é mais um sujeito distante, prisioneiro da grade escolar. Ambos estão comprometidos na troca reciproca de experiências (Pontuschka, 1993: 95).

\section{O Trabalho Grupal}

A análise de um trabalho em grupo deverá contemplar, também, a dimensão subjetiva, uma vez que as relações entre as pessoas que se mobilizam para realizar uma tarefa constituem um dos fatores de maior importância para o processo. O referencial teórico adotado utiliza os conceitos psicanalíticos para compreender situações do cotidiano escolar pela análise das relações estabelecidas entre professores, alunos e conhecimentos. Valadares (2002), o autor que escolhemos como guia em nossa interpretação, faz uma aplicação dos conceitos psicanalíticos de René Käes para tentar compreender o comportamento de um grupo de professores diante de uma proposta de trabalhos coletivos e interdisciplinares em uma escola da cidade de Belo Horizonte; as angústias, os dilemas e as resistências do grupo são analisados dando um quadro de como eles construíram as relações necessárias para a realização das tarefas propostas.

Em nosso trabalho, procuraremos entender o que manteve as professoras mobilizadas em torno da tarefa de construir um planejamento interdisciplinar, apesar dos conflitos e das dúvidas em relação à aplicabilidade das perspectivas interdisciplinares propostas. Vamos, para isso, utilizar o conceito de Aparelho Psíquico Grupal (APG), que se refere a uma construção psíquica comum aos membros, necessária para estar em grupo e também fundamental para pensar os efeitos do agrupamento sobre as formaçôes do sujeito do inconsciente. (Valadares, 2002: 23). A teoria psicanalítica de Käes procura entender as relações tanto do grupo quanto do sujeito do grupo e, para isso, analisa estas relações em três dimensões: a intrapsíquica, o sujeito e seus grupos internos, suas relaçóes inconscientes; a intragrupal, do sujeito com os outros indivíduos do grupo; a histórica, que remete à cadeia de gerações e à transmissão psíquica entre elas.

Para Käes (1997), o grupo é uma entidade pluripsíquica organizada, com suas práticas e discursos orientados por formaçōes inconscientes. A ponte entre os espaços psíquicos, inconscientes, individuais, é o que podemos entender como Aparelho Psíquico Grupal, que além de articular os espaços intrapsíquicos, organiza os vínculos intersubjetivos dos diversos sujeitos do grupo. O APG começa a funcionar a partir do primeiro grupo no qual somos inseridos, a família, organizando a identidade psíquica do indivíduo; quando nascemos, nossos pais e familiares projetam nossos comportamentos e nos guiam nessa direção; quando participamos de um grupo de trabalho, a instituição que convoca, e que também é um grupo anterior, é quem irá indicar nossas posições no grupo. Inicialmente, o sujeito aceita essa determinação do grupo como sendo uma forma de ser recebido como integrante. Mas aos poucos essa sensação vai dando espaço para a necessidade de recuperar a individualidade. Ele terá que se distanciar, olhar de fora para dentro para não se perder naquela interação. A idéia do Käes é essa: existem dois eixos no processo grupal: um sincrônico, caracterizado pela tensão entre identificação e diferenciação, e o outro diacrônico, caracterizado pelas etapas que o grupo já percorreu.

No eixo sincrônico, o APG funciona em dois momentos diferentes, antagônicos: um pólo isomórfico e um pólo homomórfico. O pólo isomórfico pode ser identificado como a situação em que o espaço individual e o grupal se confundem; os indivíduos assumem os papéis designados pelo grupo e a relação entre os participantes não suporta a diferença. O pólo homomórfico representa os momentos de subjetivação entre os participantes, criando simbologias próprias, 
preservando a individualidade. É nesse momento que o grupo consegue conviver com suas diferenças e com seu pluralismo de idéias. Além disso, os processos de subjetivação promovem a mobilidade de papéis e lugares no grupo, inclusive a rotatividade do líder. Normalmente o grupo oscila entre esses dois pólos que, quando controlados, permitem ao grupo avançar e transformar-se lidando com as circunstâncias, adaptando-se ou rompendo com o meio social no qual está inserido.

Para facilitar o entendimento do eixo diacrônico, ou seja, das transformaçóes do grupo ao longo do tempo, Käes propóe seqüências que descrevem as organizações e as desorganizações que se sucedem no caminhar do grupo. Estas seqüências são chamadas de organizadores psíquicos grupais. O primeiro momento é chamado de momento originário, no qual o grupo é entendido pelo indivíduo como algo externo a ele, que pode sustentar os seus anseios, os seus projetos e as suas angústias, ou seja, todo o respaldo para suas mudanças, internas e externas. Mas para que isso aconteça, o grupo precisa aceitar o indivíduo como integrante; assim, o grupo passa por um momento de construção de identificaçôes. Quando o sujeito é convidado para participar de um grupo, as angústias de não ter um lugar assinalado naquele grupo fazem o sujeito tentar criar uma coincidência imaginária muito grande com o seu colega para sanar essa angústia.

Nesse momento inicial de constituição do grupo, são construidos tanto uma identificação entre cada um dos membros para a realização de seus desejos (construção narcísica comum) quanto os mecanismos de defesa e pactos contra os perigos que podem ameaçar a grupalidade em questão (pactos denegativos).

(Valadares, 2002: 28)

Decorrente deste momento originário, o primeiro organizador grupal pode ser entendido como um período de negociações entre os sujeitos envolvidos no grupo. Diante de um objeto comum, é preciso abrir mão de algumas angústias, negociar algumas exigências dos sujeitos singulares para criar condições de realizar a tarefa a que se propôs o grupo. Esta mediação entre os desejos trazidos, as angústias presentes, as expectativas dos membros e o grupo é feita, em geral, por um líder, que surge da projeção dos membros do grupo e que representa o desejo do mesmo. Durante essa fase domina o pólo isomórfico, e as exigências individuais são, pelo menos em parte, recalcadas pela ilusão de que o grupo poderá satisfazer as necessidades mais importantes.

Se o grupo avançar em seu desenvolvimento, um segundo organizador grupal caracteriza a passagem para uma nova fase: a colocação de um envelope grupal, que implica na elaboração das primeiras regras comuns do grupo. De uma forma mais simples podemos dizer que se trata de um momento de enfrentamento da desorganização, no qual os questionamentos levam o grupo a repensar posiçōes, defendendo-as ou abandonando-as. Assim, é necessário que o grupo eleja regras em comum, criando uma linguagem simbólica que irá legitimar as normas, fruto da realidade psíquica grupal.

A partir daí, o grupo abre espaço para a constituição do pólo homomórfico: a criação de uma linguagem comum, uma simbologia compartilhada, proporcionando que o sujeito e a palavra individual sejam resgatados. Nas palavras do autor (Valadares, 2002): Os processos de subjetivação que são decorrentes dessa fase promovem a mobilidade de papéis e lugares no grupo, inclusive a rotatividade do lider.

A diferenciação entre o indivíduo e o grupo no espaço do APG assume sua forma mais avançada a partir do terceiro organizador grupal, a fase mitopoética: 
A interdisciplinaridade e o trabalho coletivo...

Nessa fase, o grupo surge como uma organização simbólica de relaçôes de diferença entre cada sujeito no grupo. O grupo não é mais um prolongamento dos sujeitos, mas resultado de uma fase personalizante com a contribuição de cada um. Em sintese essa fase consiste, para o sujeito singular, na ampliação dos limites de sua individualidade.

(Valadares, 2002: 30-31)

Abaixo sintetizamos os elementos constitutivos dos dois eixos no processo grupal:

\section{Sincrônico}

(tensão entre a identifi-

cação e diferenciação)

\section{Diacrônico}

(etapas percorridas pelo grupo organização e desorganização)

\section{$\downarrow$ \\ Polo Isomórfico \\ (espaço individual e grupal se confundem)}

\begin{abstract}
Organizadores Psíquicos Grupais
Momento orginário (convocação)

Primeiro organizador (negociação)

Envelope grupal (regras comuns)

Fase mitopoiética (conspiração grupal)
\end{abstract}

O problema do grupo, em geral, é encontrar instrumentos que permitam enfrentar os sucessivos desafios e as demandas da realidade. Diante das transformaçôes pelas quais o grupo passa, muitos momentos de descontinuidade ou ruptura geram crises que podem ser decisivas para o cumprimento da tarefa. Os intermediários são produzidos como uma forma de readaptar os indivíduos a uma nova situação, criando uma maior aderência à realidade e mantendo o grupo produtivo. Assim, (...) o grupo avança de uma fase para outra, ou oscila de um pólo para outro, de maneira produtiva, somente se conseguir encontrar o intermediário adequado para a situação. (op.cit. p. 31).

Com este modelo pensamos poder enfrentar a questão que desde o início nos intrigou no programa de ensino: como o grupo das professoras e coordenadoras, apesar das dificuldades, conflitos e pouca confiança na teoria educacional que estava sendo proposta, por parte de alguns membros do grupo, conseguiu chegar até o final de sua tarefa grupal?

\section{Uma história do Grupo Flora}

Para contar nossa reconstrução da história do grupo de SC durante a construção do planejamento interdisciplinar, optamos por dividir a análise em fases, marcadas por comportamentos característicos do grupo em relação a dois aspectos principais: 1) a dinâmica grupal interferindo na execução da tarefa e 2) como o grupo foi construindo a leitura da interdisciplinaridade.

\section{A Fase da Concepção e Implementação do Projeto}

Consideramos esta fase a partir da realização do Congresso da Sociedade Botânica, em setembro de 1996, até a primeira reunião geral do grupo, em dezembro de 1998. Esta fase compreende o surgimento da idéia do Programa de Ensino vinculado ao projeto temático e inclui, também, toda a tramitação do projeto pela Fapesp e as gestōes para a formação dos grupos locais.

Como comentado anteriormente, o Programa de Ensino, com enfoque interdisciplinar, foi sugerido pelo órgão de fomento para socializar o conhecimento produzido no Projeto de Pesquisa e para contribuir com a revitalização da área de Botânica, que estava sendo "desprestigiada" 
pelos alunos que ingressavam nos cursos de graduação de Biologia. Pelos relatos dos participantes, fica claro que não havia experiência anterior de um planejamento interdisciplinar e nem a consciência de que sua elaboração envolveria muito mais do que mudanças de conteúdo disciplinar: implicaria novos tipos de atividades curriculares e, sobretudo, mudanças de perspectivas e atitudes.

No começo nem sabia como seria, se seria com escola, como seria o esquema; a gente tinha que pensar do zero...

(Entrevista final - C2)

Na primeira versão do projeto global enviado à Fapesp, havia uma supervalorização dos conteúdos botânicos, característica de pesquisadores que trabalhavam em áreas muito especializadas. Apesar da proposta do projeto ser interdisciplinar, a ênfase era para o conhecimento em Botânica e Biologia. O projeto do Programa de Ensino foi enviado à Fapesp e, em 1997, conseguiu sua aprovação parcial, com ressalvas quanto à metodologia a ser utilizada. A Fapesp aprovava o desenvolvimento do projeto em uma escola por cidade, a ser escolhida pelas coordenadoras de cada subprojeto e pedia mais explicaçōes sobre o trabalho a ser realizado.

Dentre os pesquisadores envolvidos inicialmente com a idéia, somente $\mathrm{C} 1$ e outra colega, tinham uma experiência anterior com a Educação e apresentavam uma preocupação com o processo pedagógico que estaria envolvido no programa de ensino.

\begin{abstract}
Para os botânicos que se reuniram nesta primeira vez, o importante era o conteúdo exclusivamente botânico; então, se imaginava... uma adequação e uma transposição direta do conteúdo sem uma preocupação maior com a questão pedagógica... eu tinha naquela reuniāo maior experiência com relação a esta questão pedagógica juntamente com uma outra professora... aqui em nossa cidade foi o local em que primeiro se recorreu ao pessoal da Educação para elaboração do projeto e depois para dar continuidade... nas outras cidades foi feita a incorporação posterior...
\end{abstract}

(Entrevista final - C1)

De fato, C1 liderou todo o processo nessa primeira fase do subprojeto de SC e convidou C2 para ser coordenadora oficial do subprojeto.

A C1 não quis (coordenar o projeto):.. "Ah! Coordenação não quero. Eu participo, mas não quero ficar como coordenadora" (disse ela) e aí me convidou. Na época eu não sabia nem o que estava fazendo, mas acabei topando, achei que podia ser interessante e fiquei subcoordenadora de SC.

(Entrevista final - C2)

Tendo em vista as ressalvas feitas pela Fapesp em relação à metodologia do projeto, o grupo gestor, composto inicialmente somente por pesquisadores da área de Botânica, sentiu necessidade de convidar pesquisadores da área de educação para integrarem na equipe. Assim, C3 foi convidada para ajudar na reelaboração do subprojeto.

Eu complementei escrevendo no projeto a parte que eu achava que era de educação, e os aspectos metodológicos mesmo... como seria a metodologia de trabalho, principalmente em relação à formação de professor; o trabalho em grupo... Ajudei fornecendo bibliografia, montando uma parte teórica do projeto, discuti depois com elas, mas disse que a minha participação estaria bem limitada, naquele momento, uma vez que estava no término do meu doutorado.

(Entrevista final - C3) 
O parecer final da Fapesp chegou no segundo semestre de 1998, aprovando o projeto. Finalmente o convite foi feito para as professoras da rede pública lideradas por PB, antiga aluna de $\mathrm{C} 1$. Com a convocação das professoras para realizar uma tarefa coletivamente, uma nova forma de organização do trabalho pedagógico, o grupo passava pelo momento originário tentando se estabelecer para realizar a tarefa proposta. A partir do momento em que este desafio foi aceito, cada uma das professoras e coordenadoras organizou, consciente e inconscientemente, representações de como seria realizar esta tarefa. Neste momento originário, o grupo Flora construiu as identificações e assinalou os lugares de cada indivíduo dentro do grupo. Passou de um agrupamento no qual havia uma identificação difusa e intensa com o objeto de desejo, qual seja, mudar a rotina da sala de aula e privilegiar o papel da Botânica, para a constituição de um grupo, com papéis definidos, em que as coordenadoras davam as diretrizes e as professoras procuravam realizá-las em sala de aula e, ao mesmo tempo, todos buscando construir uma linguagem comum. A construção narcísica comum (ser um grupo inovador e estar apoiado num conhecimento novo) que reuniu e organizou o grupo, facilmente pode ser inferida a partir da própria proposta inicial do projeto, além das falas que circulavam nos primeiros momentos do grupo. Pelo contrário, os pactos denegativos, ou seja, os pontos inquestionáveis que não poderiam ser ameaçados na constituição do grupo, somente podem ser vislumbrados a partir dos eventos sucessivos. Nos parece poder interpretar que a primazia do conhecimento disciplinar seria o critério de julgamento implícito do sucesso do projeto, apesar de explicitamente ter sido proposto um projeto interdisciplinar. Como veremos, este conflito latente será a causa de muitas discussões e até desentendimentos, sobretudo na primeira fase do projeto.

Nas primeiras reuniōes preparatórias, foi solicitado que as professoras da rede elaborassem um plano de ensino interdisciplinar. Muitas foram as dificuldades encontradas para cumprir a tarefa; a primeira queixa das professoras foi a falta de um modelo preestabelecido, ou seja, como nenhuma orientação foi dada, elas precisavam construir uma metodologia com as concepções anteriores que possuíam sobre a integração de conhecimentos. Talvez como uma forma de resistência, o grupo não conseguiu entender como poderia modificar um planejamento, que era comum, mas não coletivo, sem a devida autorização da instituição que os abrigava. Além disso, um dos membros do grupo desistiu de participar e outra professora, $\mathrm{PH}$, foi convidada em seu lugar, por PB. O primeiro modelo de um planejamento interdisciplinar se assemelhava muito a uma "colcha de retalhos", justamente pela insegurança em modificar a base curricular já estabelecida: a professora de Biologia juntou os planos de ensino das outras disciplinas e tentou amarrar conteúdos próximos, mas sem modificar as atividades curriculares. Foi a primeira manifestação do conflito entre o desejo de introduzir inovaçōes de caráter interdisciplinar e a primazia implícita do conteúdo disciplinar. No entanto, este conflito nem foi percebido pelo grupo, pois ninguém sabia como deveria ser um planejamento interdisciplinar.

A fala dos membros do grupo permite reconhecer que a liderança de C1 funcionou como intermediária em todo o processo inicial de formação do grupo; por sua vez, a elaboração do plano interdisciplinar funcionou como o intermediária para o subgrupo das professoras, estabelecendo, de alguma forma, uma liderança de $\mathrm{PB}$ e mantendo as professoras organizadas. O plano interdisciplinar, de fato, permitiu que o grupo sobrevivesse até o início oficial das atividades do Programa de Ensino, mesmo após a crise gerada com a descoberta de que seria muito mais complexo desenvolver um projeto interdisciplinar sem as receitas esperadas e com as expectativas diferentes das pessoas envolvidas. De fato, o plano foi uma atividade elaborada pelas professoras, que as tornava participantes efetivas do grupo e responsáveis pelas propostas levantadas. Por isso, não foi fácil para elas apresentar seu plano para toda a equipe do projeto, constituído, até então, de pessoas desconhecidas. Isso ocorreu na primeira reunião geral em 
que os grupos das quatro cidades se encontraram para troca de experiência e construção global e coletiva de vários aspectos da pesquisa. Neste momento C3, que já tinha terminado o doutorado, aceitou participar da implementação do projeto.

Coitada, a PH já pegou o negócio andando... eu pelo menos já estava pensando nisso desde setembro, ela entrou em novembro, foi questão de duas ou três semanas a gente já estava indo lá apresentar o trabalho. E ai a gente começou...

(entrevista final - PB)

A idéia de interdisciplinaridade foi interpretada de maneira diferente pelas outras cidades participantes e esse fato, motivo de angústia inicial para as professoras de SC, principalmente, para a PB. Elas esperavam encontrar uma definição, uma receita de interdisciplinaridade. Este primeiro encontro geral confundiu suas idéias e seus sentimentos, pois além da necessidade de estabelecer e defender seus lugares diante do grupo geral, precisavam entender qual era a metodologia com a qual deveriam trabalhar.

Em resumo, os vínculos que se estabeleceram eram decorrentes de alianças e defesas, que por um motivo ou outro faziam com que as pessoas formassem representaçóes narcísicas e imaginárias entre elas. A representação que cada uma das coordenadoras tinha em relação ao seu vínculo com o projeto e a posição assumida depois do início, parece refletir um pouco a primeira rotatividade de papéis. As professoras estavam desconstruindo seus papéis de professora transmissora e tentando construir sua identificação com o papel de professora reflexiva e orientadora de seus alunos. As identificações com as coordenadoras passaram a nortear suas posições dentro do grupo.

Nos parece que nesta fase inicial o grupo Flora buscou organizar-se em torno do desejo do outro, que aqui poderia ser representado primeiramente pelas instituições. Para as coordenadoras, o outro era a instituição de pesquisa que patrocinava o projeto, por isso elas buscaram professoras já conhecidas que responderiam à expectativa com um trabalho sério. Para as professoras, o outro era multifacetado: de um lado, a instituição universitária, representada pelas coordenadoras e, do outro lado, a escola com toda sua tradição.

\section{A Fase Inicial: o Primeiro Organizador Grupal}

Representa o período de janeiro a novembro de 1999, no qual a tarefa principal do grupo foi implementar o projeto na escola. Inicialmente, o grupo parecia estar no pólo isomórfi$c o$, com os espaços individual e grupal se confundindo e com as coordenadoras garantindo a uniformidade do clima de trabalho. A construção interdisciplinar, nesta fase, assumiu uma perspectiva mais determinada, pois durante a primeira reunião geral o grupo pode assistir a uma conferência com as professoras Bochniak e Pontuschka, que deram algumas diretrizes importantes. $\mathrm{O}$ grupo decidiu, primeiramente, trabalhar com os temas geradores de Pontuschka (1993), elegendo a "Natureza original e a natureza transformada" como tema preferencial. O planejamento previa utilizar uma praça da cidade como natureza transformada e uma área de cerrado, pertencente à Universidade, como exemplo de natureza original, o que marcou um avanço do grupo do momento originário para um começo de negociaçóes com as diferenças para realizar o objetivo comum. As professoras sentiram uma segurança maior em ter um eixo norteador para reconstruir o planejamento das disciplinas envolvidas. Os objetivos pareciam mais claros e a idéia do tema gerador entusiasmava todo o grupo, que pela primeira vez conseguiu um consenso explícito. A entrada efetiva de C3 como membro do grupo para coordenar os aspectos pedagógicos do projeto contribuiu para tornar mais atraente o delineamento do planejamento. 
O primeiro intermediário, responsável pela estruturação do grupo, foi a visita ao local proposto para ser um dos objetos de estudo: a praça central da cidade. Esta visita marcou o início de um trabalho interdisciplinar no grupo Flora. Ali mesmo o grupo começou a planejar algumas atividades a serem propostas aos alunos, envolvendo as três disciplinas: Biologia, História e Geografia. Havia um interesse claro na integração das disciplinas. Parecia, neste primeiro momento, que seria muito fácil construir um planejamento interdisciplinar, que giraria em torno da Botânica. Durante 40 dias as atividades escolares e os encontros de planejamento foram no sentido de preparar os alunos para a visita à praça, que deveria marcar uma mudança no currículo da classe escolhida (terceiro ano do Ensino Médio). O grupo viveu, neste período, o ponto mais alto da ilusão grupal de ter encontrado um meio para satisfazer todas as demandas das coordenadoras e das professoras e de se considerar como um grupo inovador. Tratava-se da explicitação consciente do primeiro organizador, que sustentava esse momento de fusão grupal. Os conflitos possíveis foram minimizados ou recalcados.

Porém, a realidade da escola era outra e isso perturbava muito o grupo. Apesar de propor atividades variadas o resultado aparente não parecia satisfatório. Leituras de textos e discussão de questōes sobre meio ambiente, música com análise de sua letra, dinâmicas para formação dos grupos com a ajuda de uma psicóloga, trabalhos em conjunto para classificação dos seres vivos, um filme sobre evolução, não pareciam assegurar que a atenção dos alunos e, conseqüentemente, a sua participação, fossem garantidas. A visita à praça com os alunos não teve resultados considerados satisfatórios por todos e foi objeto de discussão nas reuniões seguintes. Nestas reuniões começaram a aparecer os conflitos até então implicitamente desprezados: conflitos entre as coordenadoras e conflitos entre as professoras.

Feitos os ajustes no projeto, eu imaginei que nós... não que não fôssemos ter conflitos, mas não imaginei que os conflitos fossem da ordem que foram e que fossem tão intensos, porque na realidade quando começou a prática, aquela perspectiva que foi colocada no projeto foi simplesmente ignorada.

(Entrevista final - C1)

A negociação entre as áreas era dificultada pela falta de uma aceitação mútua entre as metodologias envolvidas: a C2 insistia no privilégio que deveria ser dado ao conteúdo de Botânica, enquanto C3 tentava introduzir aspectos de uma metodologia que envolvesse mais os alunos e chamava atenção para que a participação das professoras fosse mais ativa.

\section{PB - (...) Mas é aquela história, você querer tentar estar fazendo as coisas numa determinada seqüência e de não querer estar fazendo as coisas como sempre foram feitas.}

Ou seja, para a PB modificar o planejamento tradicional era difícil e angustiante, mas ao mesmo tempo, ela não queria continuar com o esquema de aulas anteriores. Por sua vez, começava também a aparecer a queixa de $\mathrm{PB}$ e $\mathrm{PH}$ em relação às ausências de PG nas aulas, que prejudicavam o andamento do projeto.

PH - Há momentos em que eu me sinto perdida,..., para onde eu vou agora? (...) Com a PB é mais fácil, pois a gente se vê toda manhã e (...) sempre conversa (...) parece que assegura o elo. (...) Parece que a gente não fica naquela solidão cósmica. (...) Eu me sinto com algumas resistências sérias a um projeto coletivo. (...) A própria estrutura da escola, o próprio funcionamento é muito estanque, compartimentado. (...) Para mim é um desafio... É uma tentativa de abrir um caminho diferente em relação ao ensino-aprendizagem. 
A proposta de um diário das professoras que auxiliasse na programação não funcionou, neste momento, como intermediário para superar os conflitos, pois foi interpretado como sendo uma atividade burocrática e não criativa. Na época, o grupo estava interessado em encontrar uma linguagem comum para facilitar o trabalho coletivo e também para ajustar seus relatos individuais visando maior agilidade na elaboração dos relatórios para o órgão de fomento.

Outro fato ocorrido neste período foi a entrada de uma professora de Artes, PA, no grupo. Apesar de Artes não ser uma disciplina do currículo do terceiro ano, as outras professoras solicitaram a sua inclusão no programa porque muitas atividades necessitavam de uma orientação artística e, também, para auxiliar o grupo a analisar o desenvolvimento cognitivo por meio dos desenhos dos alunos, que tinham sido propostos na atividade da praça como forma de envolvê-los com o tema. Logo após sua entrada, PA ajudou os alunos a confeccionarem seus desenhos para o Concurso de Logotipo para o Programa. Tratou de uma atividade que envolveu todas as cidades e que tinha por objetivo estimular os alunos na construção de um logotivo que representasse o Programa de Ensino. Desta forma, todas as classes integrantes do projeto, nas diferentes cidades, participaram do concurso e a ganhadora foi uma das alunas de SC, evento que reforçou a aceitação de PA no interior do grupo.

O encaminhamento dado às atividades havia ameaçado os limites da disciplina de Biologia, considerado o carro-chefe do programa, e privilegiado o papel da História, provocando uma reflexão sobre os rumos que o grupo tomava em termos de interdisciplinaridade. Porém, em vários momentos, houve um recuo para a situação inicial, na qual a Biologia deveria ser privilegiada autorizando, no máximo, que as outras disciplinas seguissem os passos determinados. De fato, o problema do diálogo efetivo foi mais amplo, pois as orientaçōes das coordenadoras focalizavam pontos diferentes que não tinham sido unificados e o processo de planejamento, em várias circunstâncias, foi pouco articulado. Talvez por causa disso, em vários momentos, as professoras pareciam agir executando ordens, mais do que planejando, e como resultado, a atuação em sala de aula estava sendo diferente do planejado.

Além disso, um problema específico estava aumentando de importância. As falas da PG, às vezes, provocavam irritação, uma vez que ela insistia que não tinha problemas, pois tinha tudo já planejado para suas aulas, com material suficiente e, inclusive, o tempo era suficiente até para atender à demanda dos alunos que lhe pediam que trabalhasse com outros temas. Essa fala soava como uma provocação, pois ia de encontro às tentativas de uma programação conjunta e articulada, mas ninguém realmente externava sua opinião a respeito, esperando que o tempo resolvesse o problema. Era necessário um intermediário que arrancasse todo mundo da rotina conflitiva e colocasse uma nova perspectiva.

De fato, o mal-estar continuou até que C3 sugeriu a idéia de um painel que serviria para os alunos visualizarem a integração dos conteúdos por meio da elaboração, em pequenos grupos, de uma síntese do que havia sido visto até então. Dessa forma, esta poderia ser uma atividade de avaliação da aprendizagem dos alunos e, ao mesmo tempo, serviria para dar visibilidade do projeto para toda a escola. No encontro semanal com os outros professores, o HTPC, as professoras apresentaram a idéia do painel para os membros da escola. Estes não só apoiaram a idéia como, pouco a pouco, foram sendo capturados, também, pelo desejo de difundir o trabalho que estavam desenvolvendo com os seus próprios alunos. Surpreendentemente, quase todos os professores mantinham pequenos projetos acontecendo em sala de aula ou em seus laboratórios; quem ainda não tinha, envolveu-se engajando os seus alunos em algum projeto. Essa recepção positiva na escola motivou o grupo a investir na realização de uma exposição que agora tomava outra dimensão. A idéia foi sendo ampliada e o painel começou a virar exposição. O planejamento desta atividade restabeleceu o clima de colaboração e de otimismo de grupo. 
Seria uma volta ao pólo isomórfico e à ilusão grupal? Em nossa interpretação o sucesso dessa nova iniciativa deveu-se ao acoplamento de vários fatores: de um lado, o grupo já tinha avançado em sua organização e as professoras e as coordenadoras já sabiam lidar melhor com a realidade e assumir suas tarefas de maneira cooperativa. Por outro lado, a tarefa possibilitava o convívio fora do ambiente da sala de aula, rompendo os conflitos entre o disciplinar e o interdisciplinar. Para os alunos era uma novidade sem o sabor chato da rotina cotidiana; para as professoras consistia uma libertação, pois não precisavam se preocupar com um conteúdo específico disciplinar a ser ministrado, podendo introduzir originalidade aos conteúdos envolvidos. Também não podemos deixar de lado o papel motivador do reconhecimento dos colegas da escola que aderiram à exposição e que prestigiaram a iniciativa do grupo.

Simultaneamente, a devolução do relatório da Fapesp, pedindo maiores informaçōes sobre o andamento do projeto em SC, contribuiu para sustentar o grupo, nesta fase. É importante salientar que o grupo, estimulado por C1 e C3, fez a opção de destacar no relatório os resultados obtidos, enfatizando as fases de conflitos e avanços durante a formação da equipe e da construção do trabalho interdisciplinar. E essa opção não pareceu ser bem compreendida pelo parecerista, que considerou que o projeto estava sendo mal sucedido em SC. O grupo se organizou para refazer o relatório e, ao mesmo tempo, preparar a exposição. Os conflitos entre as áreas de Educação e Botânica ainda se mantinham e uma tentativa de contornar a situação foi deixar a redação final do relatório a cargo das coordenadoras, tendo as professoras e estagiárias a tarefa de cuidar mais da exposição. Por outro lado, conforme a exposição foi tomando forma, com parte dos alunos se envolvendo na confecção dos mapas, painéis e cenários, as professoras passaram a sentir-se capazes de realmente construir uma atividade que, na visão delas, tinha uma característica interdisciplinar: o coletivo integrado. A participação de toda a escola encheu as professoras de confiança e orgulho, mas ainda havia a frustração por não conseguirem que toda a classe participasse: isso as incomodava, tirando um pouco o brilho do resultado positivo conquistado. Numa entrevista, ao final da exposição, os alunos comentaram suas impressões:

\begin{abstract}
Ah, a gente fez tudo junto, assim... Não foi a maioria da classe, mas o pessoal que estava lá com a gente trabalhou bastante. Foi uma maneira assim, diferente da gente estudar as matérias, mas eu achei que faltou assim... que a gente ficou um pouco defasado das matérias de Biologia, História e Geografia este ano, por causa do projeto. Assim, muitas aulas, a gente se dedicou mais a fazer a exposição do que a estudar. Valeu a pena, assim sabe...
\end{abstract}

(Aluna AC)

É importante comentar que, pelo fato de o projeto ter sido aplicado na terceira série do Ensino Médio os alunos e as professoras, com muita frequência entravam em crise com relação ao desenvolvimento do conteúdo para o vestibular. Porém, numa entrevista realizada com os alunos no final do projeto, foi possível perceber que eles haviam resignificado o valor de um conteúdo aprendido de forma mais contextualizada no lugar da simples memorização. Eles interpretaram que essa nova forma de ensino não somente preparava para o vestibular como também para a vida.

Os cenários montados pelos alunos relataram o projeto com tantos detalhes que, ao final da exposição, alunos de outras classes e de outros períodos vinham solicitar que o projeto fosse estendido para a classe deles. Os alunos da classe piloto estavam surpresos com os resultados e orgulhosos de terem ajudado a realizar a exposição; também tinham notado que a relação deles com as professoras havia melhorado muito. 
Acho que foi uma união maior entre os alunos e os professores envolvidos no projeto... que a gente montou a exposição... desde a alguns meses que a gente vem trabalhando nesta exposiçãa, vindo de manhã e à tarde, ficando até a noite, vindo nos dias que não tem aula. Então acho que o que mais marcou foi a união entre os professores e os alunos envolvidos no projeto. O que eu não gostei foi que nem todos os alunos do projeto se envolveram tanto no trabalho.

(Aluno P.)

Em resumo, a realização do projeto teve um desenvolvimento surpreendente que se tornou um efetivo intermediário para uma fase sucessiva, mais organizada e operativa.

Um evento importante também afetou o relacionamento da PG com o restante do grupo, tornando-o muito difícil. Durante a exposição aconteceu uma briga envolvendo PG e $\mathrm{PH}$, que se ofenderam na frente dos alunos e cortaram as relações definitivamente. A partir desse momento não houve mais condições para trabalharem juntas e o restante do grupo não procurou mediar para que o relacionamento fosse reconstruído.

\section{A Fase Final: o Envelope Grupal}

Esta fase envolve o período que vai das reuniōes após a exposição, em novembro de 1999, até o final do projeto, em dezembro de 2000. Alguns eventos caracterizaram esta fase mostrando que o grupo evoluiu ao superar conflitos e elaborar algumas regras, explícitas ou implícitas, que ajudaram a sustentar o processo até o final.

$\mathrm{Na}$ passagem para uma nova fase, encontramos um segundo organizador grupal: a colocação de um envelope grupal, que implicava em elaborar regras e normas a partir da realidade grupal. Estas regras levaram a PG a perceber que ela não teria tempo disponível para dedicar ao projeto da forma necessária, como acordado no projeto aprovado. Durante dois meses, as reuniōes do grupo tentaram mostrar para a PG que ela estava se excluindo do grupo ao faltar nas reuniões, ao deixar de cumprir o planejado em sala de aula, ao deixar de contribuir com as iniciativas das outras, ao ceder, sem pensar nas conseqüências, aos pedidos dos alunos. De alguma forma o grupo considerava PG uma ameaça implícita aos pactos iniciais que sustentavam o grupo, por isso continuou a pressioná-la implicitamente.

No entanto, este problema foi inicialmente deixado de lado por causa de uma outra preocupação: a apresentação, no Encontro Perspectivas do Ensino de Biologia (EPEB), de um artigo escrito pelas professoras. $\mathrm{O}$ artigo, que havia sido proposto por $\mathrm{C} 3$, contava um pouco da experiência com a exposição do ano anterior; os pontos principais destacavam o trabalho coletivo, o diálogo reflexivo, as questôes de ensino e pesquisa. As reflexões, apresentadas no artigo, mostravam que o grupo tinha feito muitos progressos, principalmente com relação à postura das professoras frente ao coletivo.

PB - (...) uma coisa que é importante, e que a gente aprendeu é que o trabalho desse tipo, um trabalho inovador, um trabalho que busca desconstruir toda uma visão de mundo para construir uma nova visão, ele não ocorre sem lutas e conflitos, isso é inerente.

A participação no Encontro marcou um ponto alto na satisfação de $\mathrm{PB}$, que teve um desempenho bastante louvado pelos participantes da sessão na qual apresentou o trabalho.

Logo depois do Encontro, duas decisōes foram tomadas. A primeira foi trabalhar com o tema Evolução, seguindo as sugestôes dos PCN, que tinham acabado de entrar oficialmente nas escolas públicas. Esta foi a proposição de uma das coordenadoras como forma de minimizar a angústia das professoras em relação à proximidade da metodologia da proposta do projeto com o movimento pedagógico na escola. As professoras do grupo pareceram gostar da escolha, pois 
podiam abandonar os planejamentos antigos e construir uma estratégia interdisciplinar, desta vez sustentados por uma política educacional. PH sentiu um pouco de dificuldade em pensar nessa linha, mas acabou achando um caminho, ajudada pelos outros integrantes do grupo. A satisfação implícita do grupo em estar preparado para uma mudança desse tipo apareceu, também, nos relatos sobre a situação da escola, na qual os outros professores, que não passaram por nenhum tipo de discussão sobre uma mudança metodológica, estavam perdidos e sem saber como fazer.

A segunda decisão foi a desistência da PG de participar do grupo: a razão oficial foi que ela não tinha conseguido aulas para o ano de 2000 na escola, porém, de fato, o importante foi que já havia uma tendência antiga para a exclusão dela do grupo. Não houve tentativa em encontrar uma solução, por exemplo, aceitando-a como professora auxiliar, como foi com a PA, ou mandando um pedido formal à escola para que cedesse a aula de Geografia da classe escolhida para a PG. Uma das conseqüências dessa saída foi a sobrecarga de trabalho para a PB, que agora deveria abordar também os aspectos geológicos da evolução. O ponto fundamental era que ela devia estudar muito para atender às expectativas do grupo com relação ao seu desempenho docente, assim, começou a manifestar algumas resistências em relação às iniciativas do grupo.

O grupo se mobilizou para enfrentar o novo desafio: as professoras começaram a procurar livros que respondessem às expectativas que elas tinham com relação ao planejamento, principalmente livros sobre Evolução. PA relatou que estava substituindo a professora de Português e que precisava de material para falar um pouco da história da arte; o grupo sugeriu uma bibliografia, disponível na biblioteca da escola, que, inclusive, continha registros de como o povo primitivo dos Maia se expressava através de desenhos. Enfim, o grupo parecia ter encontrado novo ânimo para desenvolver o planejamento com maior integração com o resto da escola. Para que elas pudessem melhor planejar o tratamento a ser dado ao tema, elas começaram determinando o número de aulas e os conteúdos dispensados para cada assunto.

Uma maneira de iniciar o tema da Evolução foi mediante a discussão, em classe, de um texto antigo sobre a origem da vida. PB mostrou-se insegura quanto sua preparação teórica sobre o assunto e quanto à participação e ao interesse dos alunos. Reclamava também pela falta de um planejamento mais detalhado envolvendo questóes motivadoras para os alunos. Mais uma vez uma circunstância casual modificou o rumo do grupo: um dos monitores lembrou-se que estava sendo preparada uma exposição, organizada pelos alunos da graduação do curso de Biologia, sobre o tema evolução: a Paleoexpo; os alunos poderiam visitá-la e familiarizar-se com o tema. C3 então sugeriu um aproveitamento maior do evento: PB poderia convidar os alunos a produzirem uma história em quadrinhos para ser exposta na Paleoexpo, o que os incentivaria a lerem e discutirem o texto proposto. Todo o grupo ficou entusiasmado com a proposta, vislumbrando a possibilidade de um novo envolvimento dos alunos, como tinha acontecido na exposição anterior. Para motivar os alunos e vencer as resistências de $\mathrm{PB}$, todas as professoras e os estagiários participaram da aula na qual deveria ser realizada a leitura e colocado o convite para os alunos. Entretanto, a reação dos alunos foi pouco entusiasta, desanimando, também, as professoras. A estagiária-pesquisadora insistiu apontando a possibilidade de atividades e encontros interessantes durante a exposição, mas o entusiasmo dos alunos não aumentou. Logo depois, no intervalo, um dos alunos tentou explicar que o grupo não acreditava na Evolução como apresentada no texto e sugeriu que ele e seus colegas poderiam, ao invés de montar a história em quadrinhos com a versão evolucionista, fazê-lo com a versão criacionista.

$\mathrm{Na}$ reunião sucessiva, o pedido dos alunos foi discutido; C2 achou muito perigoso reproduzir a idéia criacionista, mas $\mathrm{C} 1$ e $\mathrm{C} 3$ ficaram entusiasmadas e citaram até novos estudos feitos nesta área. O grupo acabou concordando e forneceu material de apoio para os alunos, que se reuniram em duas equipes para realizar a tarefa: os criacionistas e os evolucionistas. 
Apesar das resistências de $\mathrm{PB}$, que temia um fracasso da iniciativa, o trabalho em classe foi realizado; inclusive o grupo criacionista pediu auxílio também a pessoas ligadas à sua religião para obter mais informações para sua história em quadrinhos. Um detalhe importante é que havia começado a greve dos professores do Estado e os alunos da classe piloto, mesmo não tendo aula, compareceram para elaborar a história em quadrinhos, respeitando assim, o compromisso com a data da Paleoexpo.

Durante a exposição, porém, houve um embate entre os alunos da graduação e os alunos do Ensino Médio: para os futuros biólogos era uma ofensa expressar opiniōes "não científicas" e exigiram que os cartazes criacionistas fossem retirados. Os alunos do projeto não se intimidaram:

Por que não podemos expor livremente nossas idéias, se o criacionismo tem adeptos no mundo todo e pesquisas são feitas para sustentar essa idéia? Inclusive dentro da Biologia existem pesquisadores que são criacionistas.

No entanto, os graduandos, descontrolados e irados com a opinião dos alunos do Ensino Médio, não queriam saber de argumentos. No fim da discussão, os alunos do projeto retiraram seus materiais, alegando que a última coisa que pretendiam era ferir a crença dos futuros biólogos.

Enfim, a realização da Paleoexpo foi bastante significativa para o grupo e para os alunos, por mostrar os resultados positivos que até então não tinham sido vistos. Este evento serviu de intermediário para realizar a mudança definitiva da liderança para o lado da Educação. $\mathrm{O}$ grupo tinha entrado no pólo homomórfico, com a busca da criação de uma linguagem comum, a linguagem interdisciplinar. $\mathrm{O}$ planejamento do ano já havia deixado transparecer que a Botânica não era mais o conteúdo principal isoladamente, pois o tema escolhido pelo grupo perpassava todas as disciplinas envolvidas: a evolução dos seres vivos no tempo e no espaço.

$\mathrm{O}$ entusiasmo do grupo pelo comportamento equilibrado e maduro dos alunos durante a exposição foi quebrado pela notícia de que $\mathrm{PH}$ e uma monitora deixariam o projeto por razões pessoais. Com isso, $\mathrm{C} 2$ e $\mathrm{PB}$ pediram para que o grupo discutisse novamente as possibilidades de renovação do projeto na perspectiva de dar continuidade às atividades em sala de aula. Particularmente, C2 achava que não deveria ser feito o pedido de renovação, pois o trabalho a estava sobrecarregando. Por sua vez, PB reclamava por não ter mais ninguém para trabalhar com ela na sala de aula, tendo perdido primeiro PG e depois $\mathrm{PH}$.
$P B-\ldots$ acho que um pouco é em função da gente estar sem Geografia, cobrindo aí um espaço, as dificuldades que existem com a sala, um desgaste muito grande, o cansaço (...). Quanto menos pro- fessores trabalhando com a classe mais difícil fica (...) eu vou pensar duas vezes em relação a estar renovando... eu estou sentindo dificuldades com as questöes de casa, por conta do projeto. (...).

A discussão continuou por várias semanas, mas C1 e C3 eram favoráveis à continuidade, sobretudo pelo envolvimento dos alunos, que estavam pedindo uma retomada do debate entre eles e os alunos da graduação: eles queriam argumentaçôes consistentes em defesa de suas crenças, tanto da parte deles quanto da parte dos graduandos. $\mathrm{O}$ relatório final foi enviado à Fapesp junto do pedido de renovação, mesmo com o parecer contrário de C2 e PB. De alguma forma, implicitamente, pareceu que a decisão final dependeria da resposta da instituição financiadora.

No entanto, a influência da C2 sobre o grupo tinha diminuído bastante, apesar de sua posição de coordenadora oficial, pois ela não conseguia representar a opinião da maioria em relação à função da disciplina de Artes e ao significado que deveria ser atribuído às iniciativas dos alunos: o grupo parecia ter conseguido elaborar uma linguagem e uma visão comum 
diferente sobre esses temas. Também a entrada de um novo professor de História contribuiu para animar o grupo com sua receptividade em relação ao trabalho interdisciplinar.

No entanto, de repente, dois novos eventos pareceram acabar definitivamente com a experiência: a saída do novo professor de História, que substituiu PH, e a resposta negativa da Fapesp em relação a uma possível renovação do projeto. A série de reunióes extra que seguiram iniciaram num clima de desânimo que deveria decretar oficialmente o fim do grupo. Uma primeira surpresa foi que todos compareceram nas reuniōes e se organizaram para discutir objetivamente o problema, inclusive a professora $\mathrm{PH}$, que já havia se desligado do grupo. Uma segunda surpresa foi que PH decidiu voltar para a sala de aula, pois a aposentadoria dela ainda não havia sido publicada e a perspectiva de uma segunda exposição do trabalho dos alunos na escola a estava animando bastante. Uma terceira surpresa foi que, de fato, a justificativa do relator da Fapesp para negar o pedido de renovação parecia pouco consistente e facilmente refutável. Em particular, ele criticava os desacertos do grupo e não considerava que, na educação, a interpretação das falhas na programação ou na execução pode constituir um resultado bastante positivo e útil para os planejamentos futuros. Assim, C3 ofereceu-se para a tarefa de reelaborar o relatório final e reiterar o pedido de renovação para a Fapesp, focalizando as últimas conquistas do grupo quanto ao planejamento e aos trabalhos dos alunos. Finalmente, todos concordaram que seria um desperdício grande não levar a experiência até sua conclusão natural e não divulgar seus resultados interessantes que estavam sendo cobrados pelo projeto geral. Assim, foi enviado um novo pedido de renovação do subprojeto.

$\mathrm{Na}$ verdade, este foi o último intermediário do grupo. As reuniōes que seguiram, mesmo sem saber se o pedido seria aceito, mostraram que o grupo tinha atingido a fase de envelope grupal, ou seja, de organização compartilhada. As discussões do planejamento eram mais fáceis de realizar, pois as professoras e as coordenadoras chegavam a colaborar mutuamente sem dificuldades. A resposta da Fapesp chegou dois meses depois do encaminhamento do pedido, renovando o projeto até o final do ano.

Os desafios enfrentados nos encontros seguintes, de planejamento, mostraram que o grupo já aceitava a pluralidade como normal, resultado do caminho realizado com o projeto. $\mathrm{Na}$ última reunião do ano, o grupo encerrou suas atividades grupais, mas assumiu o compromisso de relatar as experiências com a elaboração de um livro. Nos meses seguintes, algumas das professoras e monitoras produziram seus trabalhos revelando algumas facetas que não foram percebidas durante a caminhada: seu entusiasmo pelo trabalho interdisciplinar e envolvimento com o grupo.

Os eventos da fase final do projeto mostraram uma evolução nas duas características aparentemente contraditórias do grupo: de um lado, sua grande dependência dos eventos externos, de outro lado, sua capacidade de explorar essa dependência. As respostas dos alunos, positivas ou negativas, ainda influenciavam muito o clima de entusiasmo ou de desilusão vivenciado pelo grupo e, também, as decisōes que eram tomadas em sala de aula. Analogamente os incentivos das instituições ou dos colegas afetavam o rumo das discussóes e das decisões tomadas no planejamento das atividades do grupo. Porém, a vontade de se reunir e de permanecer juntos, de um lado, transforma os eventos em ocasiāo para experimentar algo de novo e, de outro lado, já influenciavam para que o planejamento assumisse uma perspectiva de maior organização. A rotina cotidiana ainda estava amarrada, em parte, ao currículo disciplinar, porém, já havia um planejamento marcado também pela experimentação bem mais livre das ocasiões interdisciplinares na docência. De alguma forma, durante a fase final, o grupo aprendeu a lidar com as queixas e insatisfaçóes devidas à adesão limitada dos alunos às propostas docentes, explorando tanto um roteiro mais interdisciplinar, quanto iniciativas eventuais nas 
quais o envolvimento dos alunos tornava-se surpreendente. A maneira como foram enfrentados os desafios finais - cansaço, recusa da renovação do projeto, saídas de membros do grupo - revela que o grupo tinha atingido um amadurecimento em sua proposta de trabalho coletiva: a visão interdisciplinar não estava influenciando somente na escolha do tema a ser trabalhado, mas também na maneira grupal de abordá-lo. A mudança final pode ser resumida dessa forma: no início das atividades grupais, a escolha era mais entre uma proposta grupal e uma individual, ou seja, a dúvida era se o grupo auxiliaria a desenvolver um projeto inovador ou se seria melhor cada um elaborar seu próprio planejamento individual. No final não havia mais dúvidas quanto ao auxílio fornecido pelo trabalho grupal: a escolha era entre continuar com uma atividade grupal ou desistir da inovação, ou seja, a dúvida era se o grupo estaria suficientemente preparado para enfrentar as dificuldades que a sala de aula apresentava.

\section{Algumas Considerações Finais}

Podemos finalizar com algumas considerações sobre todo o processo. É nossa opinião que o material produzido com a realização do projeto é muito rico em detalhes e teria permitido analisar a mesma vivência sob outros ângulos. Escolhemos apenas uma das possibilidades, a que focalizava o trabalho e a dinâmica grupal, com a intenção de mostrar um dos aspectos mais importantes que estão envolvidos em um trabalho interdisciplinar. Nossa descrição e interpretação permitem desenvolver consideraçóes bastante importantes para projetos semelhantes.

Em primeiro lugar, nos chamou a atenção a constituição do grupo. O projeto original era certamente inadequado, pois desconhecia quase totalmente as dificuldades de um trabalho interdisciplinar e até mesmo de um processo de atualização de professores do Ensino Médio. Apoiava-se completamente no poder de motivação de um conteúdo novo e interessante na área de Botânica. Felizmente, o grupo de SC foi convocado por uma coordenadora com visão educacional mais ampla, assim, convidou para o grupo professoras e colaboradoras conhecidas. Mesmo assim, a força do convite não capturou totalmente os integrantes, pois a perspectiva sobre as possibilidades de trabalho das professoras era parcial, não incorporava totalmente o saber delas e deixava espaço para as divergências, principalmente entre as coordenadoras. Isso pode ser visto mesmo na fase da ilusão grupal, ou seja, do grupo imaginar que o projeto teria um trânsito fácil e um sucesso imediato: a identificação dos membros do grupo com a proposta foi parcial e logo surgiram as divergências entre as coordenadoras, que se refletiram imediatamente no envolvimento e na adesão das professoras, com efeitos contrastantes. De um lado, favoreceram o aparecimento de dúvidas e de angústias, principalmente em $\mathrm{PB}$, referentes à relação entre o trabalho disciplinar e o desenvolvimento de atividades interdisciplinares. Por outro lado, facilitaram o aparecimento e o envolvimento do saber das professoras, pois as divergências entre as coordenadoras indicavam que o trabalho de inovação não estava definido $a$ priori e elas teriam voz e vez em seu planejamento. Assim, durante a primeira fase, o andamento das reuniōes e a atuação na escola foram perturbados por essas divergências, porém, com o passar do tempo elas foram absorvidas pelo grupo, que aumentou sua participação e aceitou progressivamente a orientação de C3, deslocando o foco para a participação de todos.

Estas consideraçôes mostram que elementos inicialmente desfavoráveis, como um convite que captura parcialmente e o aparecimento de divergências, podem ser revertidos e resultar, depois de um certo tempo, numa participação mais pessoal. Acreditamos ter sido esta participação e o que ela construiu no grupo, a razão de sua resistência diante das grandes dificuldades na fase final do projeto. 
Uma outra maneira de considerar o nascimento do grupo é através das escolhas feitas por sua liderança. Sem dúvida C1, de alguma forma, conseguiu minimizar as falhas do projeto geral cuidando para que a problemática educativa tivesse seu lugar no planejamento. Duas operações foram importantes: o pedido de assessoria e de colaboração para C3 e a autonomia concedida a PB na elaboração do planejamento interdisciplinar. Isso permitiu a entrada da realidade efetiva e de um suporte teórico para enfrentá-la num projeto altamente utópico. Sem dúvida isso provocou uma perturbação, mas garantiu um respiro maior ao projeto desenvolvido em SC. Por outro lado, a escolha de $\mathrm{C} 2$ como coordenadora oficial e, portanto, como responsável perante a Instituição financiadora, provavelmente foi a fonte de boa parte do desgaste na primeira fase da experiência. Em nossa opinião, C1 não percebeu o alcance do conflito implícito no projeto geral, nem previu que a coordenação de C2 tornaria este conflito mais explícito no desenvolvimento do subprojeto. De fato, este conflito tornou-se menos desgastante somente quando o grupo conseguiu elaborar uma linguagem comum e a orientação de C3 foi aceita como prioritária, privilegiando a participação e o envolvimento dos alunos e das professoras.

Isso nos remete diretamente a um outro ponto importante: os intermediários que permitiram o avanço do grupo. Foram eles: o primeiro planejamento interdisciplinar, o planejamento da visita à praça, o planejamento e a realização da exposição, a participação no EPEB, a saída de PG, a participação dos alunos na Paleoexpo e, finalmente, a reformulação final do pedido de financiamento. Todos eles, com exceção dos dois primeiros, foram iniciativas eventuais, não previstas, exploradas no sentido da colaboração dos membros do grupo. Isso revela uma característica do próprio grupo de explorar eventos e ocasiões eventuais, porém, revela também uma limitação na sua constituição, pois não conseguia colocar-se como caminhando com metas fundamentais preestabelecidas. Em outras palavras, foi um planejamento mais reativo do que propositivo. Provavelmente, as divergências entre as coordenadoras e a própria divisão ideológica das professoras no que diz respeito à relação entre trabalho disciplinar e interdisciplinar, dificultou a possibilidade de ter metas perseguidas de maneira comum. Somente na fase final os objetivos tornaram-se mais compartilhados e influenciaram o planejamento efetivo na sala de aula.

Um outro aspecto relevante é dado pelo desempenho dos alunos. Uma boa parte deles parecia sensível às propostas interdisciplinares que rompiam com a rotina: nestas ocasiōes eles surpreenderam as professoras e coordenadoras. Isso sugere a possibilidade de uma proposta mais ousada por parte da escola, envolvendo grupos de professores. O projeto Flora foi uma intervenção local cujo mérito foi de estabelecer uma colaboração Universidade-Escola, porém, não foi um investimento que visasse a uma mudança curricular mais profunda da escola como um todo. As diretrizes do grupo ficaram fora do alcance da escola e de seu planejamento, apesar de ter influenciado fortemente a vida cotidiana. Os efeitos importantes que a exposição introduziu na escola, fornecem uma sugestão para o sentido que a colaboração Universidade-Escola pode atingir: com a Universidade assessorando o trabalho da escola e não apenas organizando-o. Em nossa opinião, outras iniciativas tiveram um alcance maior, pois o núcleo da mudança ficou nas mãos da escola (Valadares, 2002) e de seus professores. Em nosso caso, durante o segundo ano do projeto, a escola optou oficialmente por uma perspectiva mais interdisciplinar, sem ter condiçôes efetivas para desenvolvê-la. Isso poderia ter constituído um ponto de partida para uma nova relação entre o grupo e a escola, ou seja, para um novo projeto mais amplo.

Nesta experiência foi ultrapassado o limite, já detectado em muitos outros cursos de atualização, mas não foi atingido o núcleo principal da mudança necessária. Neste caso, como em muitos outros nos últimos cinqüenta anos no Brasil (Villani et al., 2002), existiu uma tensão entre os vínculos colocados pelas instituiçóes escolares, as demandas, às vezes divergentes, 
das comunidades acadêmicas (dos docentes de ciências, dos pesquisadores da área e dos especialistas em educação) e a atuação dos professores.

Foi realizado um planejamento interdisciplinar? Com certeza houve um progresso desenvolvido de uma forma criativa e única, que nos remete às condiçôes para qualquer trabalho com educação: tempo, paciência e diálogo reflexivo. Ou seja, um projeto com interdisciplinaridade precisa que os participantes acreditem em si, nas possibilidades dos alunos e do próprio grupo. E mais, parece importante acreditar que parcerias são possíveis, como a parceria entre a Universidade e a Escola Pública, que parece receber um novo alento com iniciativas de inclusão social de seus alunos como cidadãos.

Esperamos, com este trabalho, ter dado uma contribuição à questão da interdisciplinaridade e, em decorrência do trabalho em grupo, levantado as condições que a podem tornar factível.

\section{Referências}

BRASIL. Ministério da Educação. Parâmetros curriculares nacionais. Brasília: MEC/SEF, 1997.

BOCHNIAK, R. Questionar o conhecimento: interdisciplinaridade na escola. São Paulo: Loyola, 1992.

BOGDAN, R.; BIKLEN, S. Investigação qualitativa em educação. Porto: Porto Editora, 1994.

HUBERMAN, A. M. Como se realizam mudanças em educação. São Paulo: Cutrix, 1973.

KAËS, R. O grupo e o sujeito do grupo: elementos para uma teoria psicanalítica do grupo. Tradução José de Souza e Mello Werneck. São Paulo: Casa do Psicólogo, 1997.

PONTUSCHKA, N. (Org.). Ousadia do diálogo. São Paulo: Loyola, 1993.

VALADARES, J. M. As formas e a construção da subjetividade em um grupo de professores: análise de uma prática e seus discursos. 2002. Dissertação (Mestrado) - Universidade de São Paulo, 2002.

VILLANI, A.; PACCA, J. L. A.; FREITAS, D. Formação do Professor de Ciências no Brasil: Tarefa impossível? In: EPEF, 8, 2002, São Paulo. Atas... São Paulo: Sociedade Brasileira de Física, 2002. CD-ROM.

WEIGERT, C. A interdisciplinaridade e o trabalho coletivo: variáveis envolvidas no processo de construção do planejamento interdisciplinar. 2003. 187 f. Dissertação (Mestrado) - Universidade Estadual Paulista, Bauru, 2003. 